\title{
Insulation systems of the building construtions
}

\author{
Boris Rumiantcev ${ }^{1}$, Aleksey Zhukov ${ }^{1 *}$, Dmitry Zelenshikov ${ }^{2}$, Anatoliy Chkunin ${ }^{1}$, Kazbek \\ Ivanov $^{1}$, Yuliya Sazonova ${ }^{1}$ \\ ${ }^{1}$ Moscow State University of Civil Engineering, Moscow, Russia \\ ${ }^{2}$ Modern Roofing Technologies Ltd., Moscow, Russia
}

\begin{abstract}
Constructions of the exterior insulation and decoration combines materials of different functionality and constructive solutions allows to these materials to demonstrate their efficiency to the great extent. Fire safety of buildings is mandatory requirement for building systems. Some insulating material may belong to the group of combustible, but their use in structures so as to minimize the risk of fire. On the other hand, there are special designs, in which non-flammable insulation acts as a flame retardant barrier. In the article carried systematization of construction systems used in the flat and pitched roof during the insulation and wall covering and facades. Taking into account the experience of leading firms were considered the application features of using exterior finish systems: construction solutions, requirements for materials and recommendations about the installation these systems. The article deals with the construction ventilated roofing system of two types: flat roof and pitched roof seam. In the first case, the ventilation system is created using milled insulation boards in the second - by a ventilated gap. In both cases the natural convection of air in the air cavities. Ensuring operational stability insulation is laid on the stages of production of heat-insulating materials. It is important: firstly responsible execution of all process operations associated with providing regulatory properties of materials and secondly, the performance of additional operations associated with the production of materials, working in a specific design. An example of a material whose properties can modify for a particular application, are milled mineral wool (with air channels) for systems of ventilated flat roof.
\end{abstract}

For Russia, with its harsh climate systems implementation for protect the insulation of the building envelope, aimed at creating a comfortable environment by addressing the following major construction tasks: - minimize heat loss through the insulated perimeter of the building; - exclusion of moisture in building construction and in the building; - creating a

\footnotetext{
*Corresponding author: 1j211@yandex.ru
} 
comfortable environment in the room; - increase the durability of structures; - optimization of logistics and production organization in the implementation of systems [1,2].

Building systems develop engineering services firms, manufacturing facilities which are located both in Russia and abroad. For example, slabs and mats of glass fiber produces department of insulation «SANT-GOBAIN», located in Russia, Finland, Poland, Sweden. Companies Knauf company released at the Russian enterprises full range of products for complete systems Knauf. Systems companies Rockwool are focused on the use of stone wool products, produced at the company's plant and components from suppliers. Factories Corporation TechnoNICOL produce a whole range of materials - components flat and pitched roofs, ventilated and plaster facades, floors and foundations [3, 4].

Penetration of moisture into the design due to the deterioration of its thermal insulation properties, reducing durability, deterioration humidity of the room and condition of the premises. High humidity of structures increases the risk of biological corrosion. Penetration of moisture in the material prevents a mandatory component of the building system as a vapor and waterproofing.

Comfort of the room, although it is a subjective characteristic, but depends on a number of objective parameters. Firstly, temperature control in the room. Temperatures near the floor and outer walls, as well as the average indoor temperature are indicative of comfort (or discomfort) and cause unregulated air convection [5]. Secondly, the room humidity conditions, which including depends on the water vapor permeability of insulation, humidity enclosing structure. With proper implementation of the insulation of the building envelope, the load on the HVAC system can be reduced to a minimum, which in turn helps to optimize operating costs. Thirdly, the creation of an acoustically comfortable environment due to the fact that the thermal insulation product has good sound insulation capacity and are used to protect the walls, floors and roof structures from external noise [5, 6].

Fire safety of buildings is mandatory requirement for building systems. Some insulating material may belong to the group of combustible, but their use in structures so as to minimize the risk of fire. On the other hand, there are special designs, in which nonflammable insulation acts as a flame retardant barrier. Placing insulation and features of the implementation of design solutions are also linked with the architectural aspects and, in particular, with the design of facades, roofs, interiors.

Accounting for the operating conditions of thermal insulation materials in the construction is necessary because these conditions directly determine the operating insulation resistance and therefore the durability and efficient exploitation of construction.

Technological loads on thermal insulation can divide for 3 groups: the transport and storage loads, the loads during install and exploitation. During the operation of boards exposed to temperature, weather, humid and mechanical stress. Regardless of the type of building systems, its the optimization parameter is the thermal resistance of the structure, optimization parameter of Thermal Insulation Materials (TIM) is the thermal conductivity. At the same time, the specification of TIM exploitation in each from concrete systems imposes additional requirements for thermal insulation - "restrictions", defined as "the normalized indicator".

Thermal Insulation boards which work in flat roof constructions, perceive compressive loads from higher layers of the roof pie, temporary seasonal loads and local loads of small area. The normalized indicator is compressive strength at $10 \%$ deformation. Moisturization insulation may result in the violation of waterproofing roofing or "failure" vapor barrier, which is located on the ceiling.

If the roof system reliably isolate the material from possible external fire exposure, can be applied in slabs of extruded polystyrene. In roofing systems using slabs of foam glass and stone wool. Successfully proven dual density plates. The topsheet double density boards receives and transmits these loads to the underlying layers. 
Thermal insulation in pitched roofs operate with condition "ventilated gap." Mechanical effects on it is minimalMoisturization of insulation possible in the same reasons as in the flat roof. The normalized indicator is breathable insulation. The use of fuel heater is not allowed.

In the case of using mineral-fiber materials (boards, mats) windproof solutions are need, aimed at excluding the removal of fiber erosion products. In designs using glass wool products such a fiberglass (or fiber canvas), the application of products on the basis of basalt fiber - basalt canvas. In the application of stone wool products - dual density plates are recommended.

Insulating the building envelope - the guarantor of energy saving, thus, the efficiency of energy-saving measures is defined and optimized thickness of the thermal insulation layer, and durable construction of the system as such. The durability of the building system with insulation depends on the group of factors: the correct project, quality of installation, performance products. It should be noted that the operational stability, even highquality insulation depends on the design layout and design conditions in which their operation occurs $[7,8]$.

Ventilated roof system has a number of design innovations, through which moisture evaporation increases significantly. It circulates air through the channels in the lower layer of insulation. The product might be two and three layer insulation systems with ventilation channels.

Operation of the system ventilated flat roof is based on natural air circulation. The slope of the channels is organized for the correct operation of the system, and can be both constructive and executed with the help of thermal insulation slope-formed plates. Slopeformed plates are stacked under the slab with air ducts. Air under the action of the difference in partial pressures is pulled up via a common transverse channel located along the ridge. The driving force of the process is to create a vacuum in the common channel by the force of the wind $[9,10]$. Outer roofing insulation board $40 \mathrm{~mm}$ thick evenly distributes the load on the external layer of insulation with ventilated channels.

Milled plates [6], the average density of $115-120 \mathrm{~kg} / \mathrm{m} 3$ are made from mineral wool body-oriented structure. Plates are noncombustible, their compressive strength at $10 \%$ deformation is $30-35 \mathrm{kPa}$; thermal conductivity in the dry state at $25^{\circ} \mathrm{C} 0,037-0,038 \mathrm{~W} /$ $(\mathrm{mK})$; water vapor transmission rate $-0.3 \mathrm{mg} /(\mathrm{m} \cdot \mathrm{ch} \cdot \mathrm{Pa})$; dimensions $1200 \times 600 \times(50-$ 200) $\mathrm{mm}$

Owing to the top plate, the air in ducts at $5{ }^{\circ} \mathrm{C}$ above ambient temperature. Exterior mineral wool slab roofing is the basis for the waterproofing layer. Roof slabs milled provide moisture transport along the canals to the ventilation vents (wind vane). Dimensions of the channels are: width $30 \mathrm{~mm}$, depth $20 \mathrm{~mm}$. During installation, connecting channels, as well as technological holes cut out by hand.

Roof installation is performed similar to the technique of flat roofs with polymeric membranes. Thus perform a number of additional operations. To divert water from the layer of insulation in the parapet provide gradients. To provide the necessary air flow, beams, eaves at the device, set with a small gap (air holes). Vane, with the device of the valley, set on both sides of the ridge and gravity layer increments of 6-8 m. Transverse channel 100 $\mathrm{mm}$ wide and $20 \mathrm{~mm}$ deep cut in the insulation on the roof ridge. To ensure the connection with the channels for deflectors in the upper insulating layer are punched.

Features seam pitched roof that radiation component (on a hot, summer) is presented to a greater extent and the presence of attachment double fold minimizes the possibility of direct leakage, that is, excessive moisture insulation layer. For heat transfer in a pitched roof seam characteristic are the two polar states: in the hot summer and winter conditions. 
During the summer, metal roofing accumulates heat from the sun and radiating surface becomes relatively internal layers of roofing system. The surface of the insulation layer accepts: heat flux emitted by the metal roofing and convective flow of air in the ventilated gap. Inside the heat insulating layer is formed convective heat flux due to interconnected porosity insulation and conductive flow - through the matrix material.

The direction of the resulting transfer of heat - inside the room. Mass flow (their effect on the thermal conductivity on the order of less than a heat transfer) due to the difference of the partial pressures of water vapor on the surface of the insulating layer and in a convective flow of air ventilated gap, as well as the partial vapor pressure for steam insulating layer and on the surface of the insulation.

In summer, heat insulation acts as a heat shield the interior from the exterior excess heat. In winter, the insulation acts as a heat shield the interior from the outside cold. Heat transfer in a pitched roof seam causes not only create comfortable conditions in the room (roof space), but also determines the durability of the whole system. For the winter pro-heating of metal roofing due to solar radiation is negligible and radiation component can not be ignored. Heat flow is directed to the outside from the inside premises, and insulation works as a component of heat-insulating building envelope.

There is two systems of air ventilation in the pitched roof systems and roof, it's ventilation of roof and ventilation roof space. Natural ventilation of attic through louvres skylights located on pitched roofs, inefficient due to the irrational arrangement of ventilation holes on the same level in roughly equal aerodynamic coefficients. The organization of ventilation, while ensuring the required air exchange is essential to obtain a complete washing of outside air total roof space. When placing an unproductive ventilation holes in the roof diffuse dormers this position is not satisfied. In the attic are formed zones with stagnant air. Ventilation holes under the eaves of the roof may be arranged in the form of a narrow slit leave between the wall and the roof (slit-like air holes), as well as individual holes placed in the eaves of the wall along the axes of the windows or partitions ("surgical" air holes). The ridge vent holes performed slot-shaped (Fig. 1). With this arrangement, during the calm air vents under the eaves of the roof work on the inflow in the ridge - on the hood.

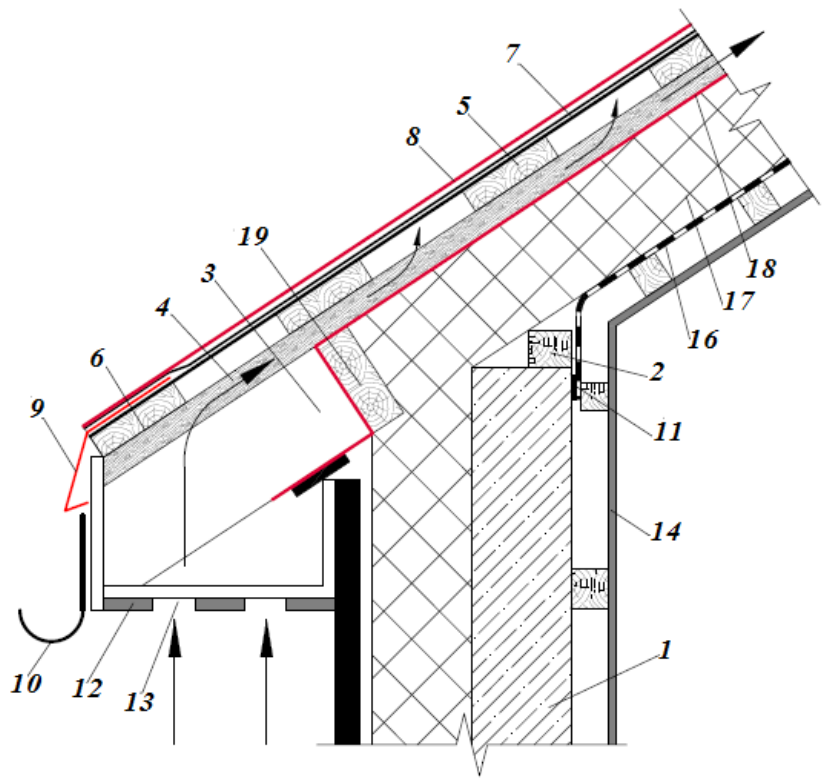

Fig. 1. Schematic diagram of an inflow of outside air through the cornice:

1 - outer wall; 2 - plate; 3 - rafter foot; 4 - counter batten; 5 - sparse batten; 6 - solid base; 7 
— carpet backing; 8 - shingles; 9 - Bracket cornice; 10 - water drainage system; 10 - gutter hook is used in case of installation of drainage system; 11 - waterproofing; 12 - Vol siding; 13 - air inlets; 14 - two layers of gypsum board; 15 - counter insulation ; 16 - steam, with sizing joints; 17 - heater; 18 - windscreen; 19 - fixing insulation boards.

The area of ventilation openings a special system of natural ventilation attic set with the calculation, depending on the heat gain in the roof space, its volume and climatic conditions of the area of building construction by a special technique. Cross-sectional area of skylights on the roof and the air holes should be 1/300-1/ 500 square attic floor, that is, for every $1000 \mathrm{~m} 2$ of attic must be at least $2 \mathrm{~m} 2$ of skylights and air holes. With this arrangement, these devices should provide cross-ventilation attic, excluding local stagnation (air sacs). Pressure in the attic should be reduced, so the area of the exhaust vents should be $10-15 \%$ more than the supply air.

This is necessary to create a draft of air. To eliminate penetration of precipitation into the attic space above the ridge slot arranged special continuous ridge aerator or made on the spot. For convenience, it is represented in the set with shingles. In order to avoid settling attic birds airways point under the roof overhang closed bars and slit - nets or special straps (spotlights).

Special ventilation of attic is arranged in the roofs of buildings of any purpose and any configuration, with wood, metal or concrete supporting structures and any kinds of roofs (made of roll waterproofing materials, steel roofing, tiles, asbestos cement sheets, etc.). It is particularly important to implement it in the roofs with thick roofing and when the location of the central heating and hot water in the attic.

It should be noted the special role of gap curtain air holes to ensure the safety of the wall portions of the roof (all rafters, plate, battens, roof overhangs), the most disadvantaged conditions. The constant flow of outside air through them is winding design.

Curtain slotted airways facilitate monitoring of the roof in the most damage-prone areas. Their presence contributes to the acceleration of warming over-roof cornice areas during periods of thaw, and with this release and gutters from icing resulting from the melting of snow in the cold days under the influence of solar radiation.

For normal ventilation combined pitched roof it should have three main elements: an opening for fresh air intake channels of thermal insulation for its circulation and exhaust vents at the top of the roof. In the case of under-eaves of firmware siding must use special elements for ventilation - the so-called soffit plate. In the case of lining, a possible option to ensure the ventilated gap is the mounting structure shown in Fig. 1. (subject to de-icing system installation).

A feature of the technology is a special module, located in front of chamber heat treatment. This module includes a drum for unwinding fiberglass mesh, glue application assembly and compression mechanism. Further surfactants carpet laid fiberglass enters the heat treatment chamber. In the chamber resulting in blowing coolant through carpet layer solidifies as a binder in the carpet and the adhesive applied to the grid. In both cases the polycondensation reaction occurs. As a result fiberglass firmly connected to the mineral wool substrate.

The result of research and technological testing was to obtain two types of products based on mineral wool with a reinforced upper layer: mineral wool products MWP VENT Plus and MWP LIGHT Plus. Product non-combustible, organic matter content does not exceed $2.5 \%$. The use of fiberglass mesh (with breaking strength in the operation of at least $350 \mathrm{~N} / \mathrm{m}$ ), which is bonded to the plate material thermosetting adhesive can improve the stability of slabs on vertical and inclined surfaces, to reduce emissions from fiber slabs to a value corresponding to the experimental error. More than 10 -fold increase operational stability of products.

Optimization of heat treatment conditions is possible with the use of special software. Computer programs written in $\mathrm{C}$ \# can perform the following tasks. Selected depending on 
the characteristics of the mineral wool mat (density, fiber diameter, the content of the binder and the fibrous inclusions, humidity and etc.), optimum differential flow resistance on the sides of the mat, the speed of heat carrier and its temperature, as well as optimize the thermal treatment chamber length and the time required upon fully curing binder.

Mineral wool products VENT Plus installed in a single layer (Fig. 2) in the following sequence. The product is fixed in the upper part of the two dowels and deploy on all length $(6 \mathrm{~m})$ to the surface of the wall. Then fix the dowels staggered. Dowels further pressed against the glass wind deflector mesh to the product, thereby increasing the reliability of the system.

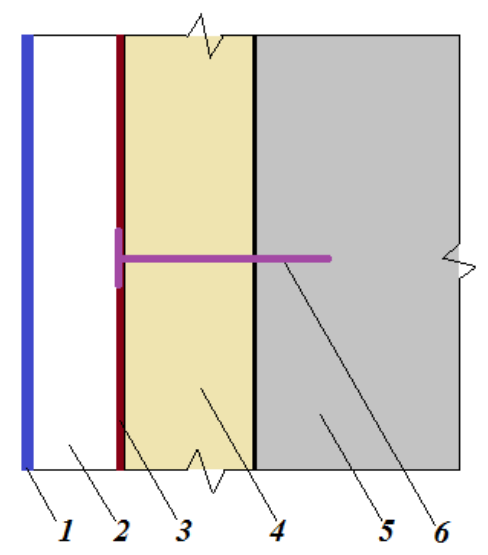

Fig. 2. Scheme of facade system with ventilated gap: 1 - outer facing; 2 - ventilated gap; 3 - fiberglass; 4 - mineral wool slab; 5 - bearing wall; 6 - insulation fastening element.

MWP LIGHT Plus is laid in two layers with a total thickness determined by thermal calculations. For the central region at the required thermal resistance of $5.1 \mathrm{~m}^{2} \cdot{ }^{\circ} \mathrm{C} / \mathrm{W}$ thermal insulation layer thickness be $200 \mathrm{~mm}$ (Fig. 3).

Length MWP LIGHT Plus up to $6 \mathrm{~m}$, which allows overlap of the roof slope either fully or to a greater part of it. The product is placed between the rafters with a reduction than is achieved and a snug fit to the rafters and fix in position. On the slopes longer than $6 \mathrm{~m}$ products are laid with joints offset.

Using the MWP with reinforced outer layer helps to minimize the number of thermal bridges, thus improving the uniformity of heat engineering thermal insulation envelope.

Fiberglass located on the surface MWP facing to ventilated gap also serves as a noncombustible windproof membrane. Thus the possibility of erosion of the fibrous material as a result of the removal of fibers by air circulating in the ventilation gap.

Cost-effectiveness analysis showed certain advantages in the manufacture and use of products with reinforced outer layer. According to technological criteria change in the manufacturing process leads to an increase in capital investment, the size of which does not exceed $2 \%$ of the production line. The increase in cost associated with the use of fiberglass and thermosetting glue, as well as depreciation does not exceed $1 \%$. At the same time in construction using of mineral wool products with reinforced outer layer excludes one production step: packing and fixation windproof layer. The use of products of great length (up to $6 \mathrm{~m}$ ) allows faster installation of thermal insulation material. These techniques improve manufacturability and reduce the installation costs of construction and installation works (by $10-15 \%$ ). 


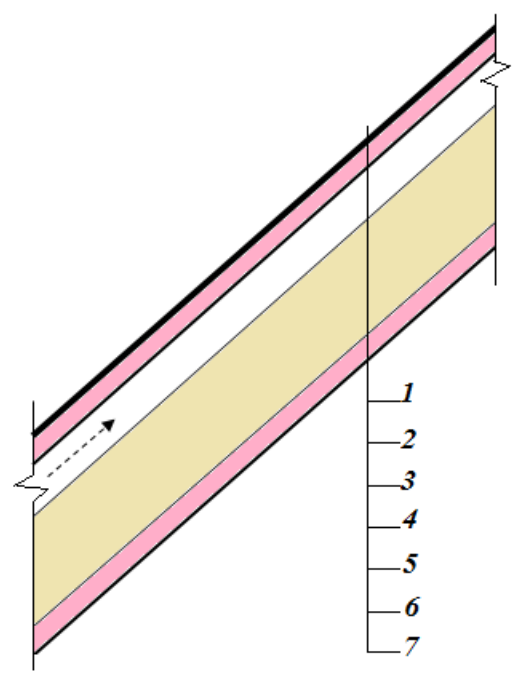

Fig. 3. Scheme of pitched roof with a ventilated gap: 1 - roofing; 2 - waterproofing; 3 - continuous (or rarefied) sheathing; 4 - ventilated gap; 5 - thermal insulation with reinforced outer layer; 6 - vapor barrier; 7 - inner lining.

\section{Conclusion.}

During operation the most pronounced are two factors of influence reinforced outer layer. Firstly by fiberglass reinforcement slab significantly increases its tensile strength (tensile). To the greatest extent this factor is manifested for pitched roofs with a slope of more than $35^{\circ}$ (for example, polygonal or mansard). In the ventilated facades this property is more pronounced when installing insulation. Further, after fixing the thermal insulation products using dowels occurs mechanical fixation of the product as well as its surface layer. Secondly fiberglass is a windscreen that prevents the destruction of the mineral wool layer by exposure to the air flow. Reinforced outer layer can significantly extend the effective exploitation of mineral wool products as in the systems of ventilated facades, roofing and ventilated systems.

\section{References}

1. A.D. Zhukov, I.V. Bessonov, A.N. Sapelin, N.V. Naumova, A.S. Chkunin. Composite wall materials. Italian Science Review, 2. 2014, pp.155-157

2. Al. Zhukov, Ye. Bobrova, D. Zelenshchikov, R. Mustafaev, A. Khimich. Insulation systems and green sustainable construction. Advanced Materials, Structures and Mechanical Engineering. Volumes 1025 - 1026. (2014) pp. 1031-1034

3. V.G. Gagarin. Thermal protection and energy efficiency in update version of SNIP "Thermal protection of buildings". III International Congress. Energy efficiency XXI century. SPb. 2011. pp. 187-191

4. B.M. Rumyancev, A.D. Zhukov, E.Yu. Bobrova, T.V. Smirnova. Technological aspects of the operational stability of the mineral fibers. Industrial and civil building 2015. №1. pp. 32-36.

5. I. Gnip, S. Vaitkus, V. Kersulis, S. Vejelis Long-term prediction of creep strains of mineral wool slabs under constant compressive stress. Mech Time Depend Mater. 2012. № 16, pp. 31-46. 
6. I. Ya. Gnip, S.I. Vaitkus, S.A. Vejelis. Prognostic evaluation of creeping deformation of mineral wool slabs with a constant compression on the basis of the initial period of strain. Building materials. 2012. № 12. pp. 40-44

7. A.D. Zhukov, N.V. Naumova, P.M. Mustafaev, N.A. Mayorova. Modeling properties of highly porous materials with combined structure. Industrial and civil construction. 2014. № 7. pp. 48-51

8. A.D. Zhukov, T.V. Smirnova, P.K. Gudkov Dual density thermal insulation in the insulation envelope of buildings. Industrial and civil construction. 2013. № 3. pp. 21-23.

9. A.D. Zhukov, T.V. Smirnova, D.B. Zelenshchikov, A.O. Khimich. Thermal treatment of the mineral wool mat. Advanced Materials Research (Switzerland) Vols. 838-841 (2014), pp. 196-200

10. A.D. Zhukov, E.Yu. Bobrova, T.V. Smirnova. Evaluation of Durability of Mineral Wool Products / // Advanced Materials Research. Vol. 1077 (2015) pp. 109-112 